\title{
Factors associated with the use of evidence-based therapies after discharge among elderly patients with myocardial infarction
}

\author{
Peter C. Austin PhD, Jack V. Tu MD PhD, Dennis T. Ko MD MSc, David A. Alter MD PhD
}

$\infty$ See related research, page 895, related commentary, page 875, and related review, page 909

\section{ABSTRACT}

Background: In an accompanying article, we report moderate between-hospital variation in the postdischarge use of $\beta$-blockers, angiotensin-modifying drugs and statins by elderly patients who had been admitted to hospital with acute myocardial infarction. Our objective was to identify the characteristics of patients, physicians, hospitals and communities associated with differences in the use of these medications after discharge.

Methods: For this retrospective, population-based cohort study, we used linked administrative databases. We examined data for all patients aged 65 years or older who were discharged from hospital in 2005/06 with a diagnosis of myocardial infarction. We determined the effect of patient, physician, hospital and community characteristics on the rate of postdischarge medication use.

Results: Increasing patient age was associated with lower postdischarge use of medications. The odds ratios (ORs) for a 1-year increase in age were 0.98 (95\% confidence interval [Cl] 0.97-0.99) for $\beta$-blockers, 0.97 (95\% Cl 0.97-0.98) for angiotensin-converting-enzyme inhibitors and angiotensin-receptor blockers and 0.94 (95\% Cl 0.93-0.95) for statins. Having a general or family practitioner, a general internist or a physician of another specialty as the attending physician, relative to having a cardiologist, was associated with lower postdischarge use of $\beta$-blockers, angiotensin-modifying agents and statins (ORs ranging from 0.46 to 0.82 ). Having an attending physician with 29 or more years experience, relative to having a physician who had graduated within the past 15 years, was associated with lower use of $\beta$-blockers (OR $0.71,95 \% \mathrm{CI}$ $0.60-0.84$ ) and statins (OR $0.81,95 \% \mathrm{Cl} 0.67-0.97$ ).

Interpretation: Patients who received care from noncardiologists and physicians with at least 29 years of experience had substantially lower use of evidence-based drug therapies after discharge. Dissemination strategies should be devised to improve the prescribing of evidence-based medications by these physicians.

Une version française de ce résumé est disponible à l'adresse www.cmaj.ca/cgi/content/full/179/9/901/DC1

CMAJ 2008;179(9):901-8
$\mathrm{T}$ he use of medications such as acetylsalicylic acid (ASA), $\beta$-blockers, angiotensin-modifying drugs (angiotensin-converting-enzyme [ACE] inhibitors and angiotensin-receptor blockers) and statins is a mainstay of secondary prevention of myocardial infarction. In a companion study published in this issue of $C M A J$, we report substantial increases in the use of evidence-based drug therapies after discharge among elderly patients with myocardial infarction over a 14-year period. ${ }^{1}$ However, despite temporal improvements, the prescribing of evidence-based drug therapies differed among hospitals in 2005.

Studies from the late 1980s to the mid-1990s showed that the prescribing of evidence-based drug therapies was influenced by patient characteristics. ${ }^{2-6}$ However, the extent to which postdischarge prescribing is influenced by patient, physician, hospital and community characteristics has not been extensively explored.

Our objective was to identify patient, physician, hospital and community characteristics associated with the use of of evidence-based drug therapies after discharge among patients with myocardial infarction.

\section{Methods}

\section{Study design and population}

We performed a retrospective, population-based cohort study using data from the Ontario Myocardial Infarction Database, a population-based database of hospital separations that occurred between Apr. 1, 1992, and Mar. 31, 2006, for patients admitted to hospital with myocardial infarction. We created the Ontario Myocardial Infarction Database by linking together several different health care administrative databases, as described in detail elsewhere. ${ }^{7.8}$ This database contains information about patients admitted to hospital with a most

From the Institute for Clinical Evaluative Sciences (Austin, Tu, Ko, Alter); the Department of Public Health Sciences (Austin) and the Department of Health Management, Policy and Evaluation (Austin), University of Toronto; the Schulich Heart Centre and Division of Cardiology, Department of Medicine (Tu, Ko), Sunnybrook Health Sciences Centre; the Department of Medicine, Faculty of Medicine (Tu, Ko), University of Toronto; the Division of Cardiology and the Li Ka Shing Knowledge Institute (Alter), St. Michael's Hospital; The Cardiac and Secondary Prevention Program of the Toronto Rehabilitation Institute (Alter), Toronto, Ont. 
responsible diagnosis of myocardial infarction. We used the discharge abstract database from the Canadian Institute for Health Information to identify patients discharged from hospital. We obtained information about coexisting conditions and the severity of the patient's cardiovascular condition from the secondary diagnosis fields in the discharge abstract database. From 1992 to 2001, diagnoses in this database were coded using the International Classification of Diseases, 9th version; beginning in 2002, the 10th version of this coding scheme was used. In a previous study that validated the accuracy of the most responsible diagnosis of myocardial infarction (which we used to select patients for inclusion in our study), we determined that the specificity was $92.8 \%$ and the sensitivity was $88.8 \%$ for patients admitted to cardiac care units. ${ }^{9}$ We excluded patients who had been admitted to hospital with a diagnosis of myocardial infarction in the year before the index admission.

We linked the admission cohort to the Ontario Drug Benefit database. This database tracks prescription medication use by all Ontario residents aged 65 years or older. Therefore, our study was restricted to patients aged 65 years or older who had been discharged from hospital with a diagnosis of myocardial infarction. We excluded patients who were discharged to complex continuing care hospitals because as their prescription medications are not covered by the Ontario Drug Benefit program. The study was restricted to patients discharged from hospital between Apr. 1, 2005, and Mar. 31, 2006. The use of each study medication was determined by examining whether the Ontario Drug Benefits database contained a record of the patient filling a prescription for the given medication within 90 days after discharge from hospital.

\section{Physician characteristics}

We linked the study cohort to the physician services claims database of the Ontario Health Insurance Plan to identify each patient's attending physician during the hospital stay. We defined the attending physician as the physician who submitted the most claims with a fee code identifying the service provided as an attending service. If there was a tie in the number of claims between 2 or more physicians, we used the following rank ordering of specialties to identify the attending physician: cardiologists, general internists, general or family practitioners, and other specialists. We previously used a similar approach to identify the admitting physician in the Ontario Myocardial Infarction Database. ${ }^{10,11}$ However, because the focus of the current study was on discharge prescribing, we felt that information about the attending physician would be more appropriate than information about the admitting physician. We established linkages between databases containing patient information using an encrypted version of the patient's health card number.

We considered the following physician characteristics: sex, number of years since graduation from medical school (as an indicator of clinical experience), specialty (categorized as cardiology, general internal medicine, general or family practice, and other) and number of patients with myocardial infarction (any age) admitted to hospital for whom that physician was the attending physician during the 2005/06 fiscal year. Physician specialty, sex and year of graduation from medical school were obtained from the Physicians Database of the Institute for Clinical Evaluative Sciences. We categorized physicians' volume of myocardial infarction cases and years of experience into quartiles (i.e., $25 \%$ of the patients within each quartile).

\section{Hospital characteristics}

For each hospital, we determined the percentage of patients who filled a prescription for a $\beta$-blocker, an angiotensinmodifying agent (either an ACE inhibitor or an angiotensinreceptor blocker) or a statin within 90 days after discharge. We considered ACE inhibitors and angiotensin-receptor blockers together for reasons described in our earlier study. ${ }^{1}$ We restricted this analysis to hospitals where at least 30 elderly patients with myocardial infarction had received treatment in 2005. We compared the characteristics of hospitals with prescribing rates of less than $80 \%$ (low-prescribing hospitals) with those having prescribing rates of $80 \%$ or more (highprescribing hospitals).

We considered the following hospital characteristics: the number of patients with myocardial infarction (any age) admitted during the study period, whether the hospital was a teaching hospital and whether it had the capability to perform invasive cardiac procedures (none, cardiac catheterization only, both coronary artery bypass graft surgery and percutaneous coronary intervention). One community hospital had the capacity to perform cardiac catheterization and percutaneous coronary intervention, but not coronary artery bypass graft surgery; we classified this hospital as a catheterization-only facility. We categorized hospital volume of patients with myocardial infarction according to the following levels: up to 100 patients, 101-200 patients, 201-300 patients and more than 300 patients.

\section{Community characteristics}

We determined the population of the community in which each hospital was located using Statistics Canada data from the 2001 census. We categorized population according to the following levels: less than 100000 people, 100 000-499 999, 500 000-1 249999 and more than 1250000.

\section{Statistical analysis}

We used a $\chi^{2}$ test to compare differences in hospital characteristics between those with prescribing rates of less than $80 \%$ and those with prescribing rates of at $80 \%$ or more. For each of the study medications, we determined whether each patient had filled a prescription within 90 days after discharge. We compared the proportion of patients who filled a prescription across different levels of the patient, physician, hospital and community characteristics. We fit multilevel logistic regression models to determine the independent predictors of a patient filling a prescription within 90 days after discharge..$^{12,13}$ We used cross-classified multilevel models that did not require physicians to practise in only 1 hospital. ${ }^{14} \mathrm{We}$ fit a separate multilevel logistic regression model for each of the 3 types of medications. The models incorporated the following patient-level variables: age, sex, cardiogenic shock, congestive heart failure, pulmonary edema, cardiac dysrhythmia, malignant disease, cerebrovascular disease, acute renal fail- 
ure, chronic renal failure and diabetes with complications. These 11 characteristics constitute the Ontario acute myocardial infarction mortality prediction model. We have described the derivation and validation of this model elsewhere. ${ }^{15}$

The multilevel logistic regression models incorporated random effects for physicians, hospitals and communities. The use of multilevel regression models allowed us to account for homogeneity in postdischarge drug use among pa- tients treated by the same attending physician, within the same hospital and within the same community. ${ }^{12}$ In these analyses, we treated the patient as the unit of analysis but accounted for the clustering of patients within physicians, hospitals and communities. An odds ratio less than 1 indicates that the odds of prescribing were lower for a given characteristic than for the reference level, whereas an odds ratio of 1 or more indicates that the odds of prescribing were greater.

Table 1: Characteristics of elderly patients with myocardial infarction who used $\beta$-blockers, angiotensin-modifying agents and statins within 90 days after hospital discharge in 2005/06

\begin{tabular}{|c|c|c|c|c|}
\hline \multirow[b]{2}{*}{ Characteristic } & \multirow[b]{2}{*}{$\begin{array}{c}\text { No. (\%) of patients } \\
\quad n=8706\end{array}$} & \multicolumn{3}{|c|}{$\%$ of patients who filled a prescription } \\
\hline & & $\beta$-Blockers & $\begin{array}{c}\text { Angiotensin- } \\
\text { modifying agents }\end{array}$ & Statins \\
\hline \multicolumn{5}{|l|}{ Patient } \\
\hline \multicolumn{5}{|l|}{ Age, yr } \\
\hline $65-69$ & $1467(16.9)$ & 81.5 & 81.1 & 87.9 \\
\hline $70-74$ & $1766(20.3)$ & 80.6 & 83.0 & 86.6 \\
\hline $75-79$ & $1873(21.5)$ & 79.9 & 79.8 & 82.1 \\
\hline$\geq 80$ & $3600(41.4)$ & 75.0 & 74.6 & 71.3 \\
\hline \multicolumn{5}{|l|}{ Sex } \\
\hline Men & $4605(52.9)$ & 78.4 & 78.5 & 82.0 \\
\hline Women & $4101(47.1)$ & 78.1 & 78.5 & 76.7 \\
\hline \multicolumn{5}{|l|}{ Shock } \\
\hline No & $8655(99.4)$ & 78.3 & 78.5 & 79.5 \\
\hline Yes & $51 \quad(0.6)$ & 76.5 & 80.4 & 84.3 \\
\hline \multicolumn{5}{|c|}{ Congestive heart failure } \\
\hline No & $6558(75.3)$ & 79.2 & 79.0 & 82.1 \\
\hline Yes & $2148(24.7)$ & 75.5 & 77.0 & 71.8 \\
\hline \multicolumn{5}{|l|}{ Cancer } \\
\hline No & $8444(97.0)$ & 78.5 & 78.9 & 80.0 \\
\hline Yes & $262 \quad(3.0)$ & 72.1 & 64.9 & 64.1 \\
\hline \multicolumn{5}{|c|}{ Cerebrovascular disease } \\
\hline No & $8450(97.1)$ & 78.4 & 78.6 & 79.6 \\
\hline Yes & $256 \quad(2.9)$ & 75.4 & 75.0 & 75.8 \\
\hline \multicolumn{5}{|c|}{ Pulmonary edema } \\
\hline No & $8627(99.1)$ & 78.3 & 78.5 & 79.6 \\
\hline Yes & $79 \quad(0.9)$ & 72.2 & 83.5 & 67.1 \\
\hline \multicolumn{5}{|c|}{ Acute renal failure } \\
\hline No & $8245(94.7)$ & 78.4 & 79.4 & 80.0 \\
\hline Yes & $461 \quad(5.3)$ & 75.5 & 62.7 & 70.9 \\
\hline \multicolumn{5}{|c|}{ Chronic renal failure } \\
\hline No & $7937(91.2)$ & 78.5 & 80.3 & 80.0 \\
\hline Yes & $769 \quad(8.8)$ & 75.8 & 59.7 & 74.6 \\
\hline \multicolumn{5}{|c|}{ Diabetes with complications } \\
\hline No & $8231(94.5)$ & 78.2 & 79.0 & 79.6 \\
\hline Yes & $475 \quad(5.5)$ & 79.4 & 69.7 & 77.9 \\
\hline \multicolumn{5}{|c|}{ Cardiac dysrhythmias } \\
\hline No & $7228(83.0)$ & 79.1 & 79.2 & 80.6 \\
\hline Yes & $1478(17.0)$ & 74.4 & 75.2 & 74.2 \\
\hline
\end{tabular}




\section{Results}

\section{Patient characteristics}

Between Apr. 1, 2005, and Mar. 31, 2006, a total of 8706 elderly patients were discharged from hospital with a diagno- sis of myocardial infarction. Lower postdischarge use of each of the 3 classes of medications tended to be associated with increasing patient age and the presence of cancer and cardiac dysrhythmias (Table 1).

Increasing patient age was associated with decreasing use

Table 2: Characteristics of physicians, hospitals and communities of elderly patients who used $\beta$-blockers, angiotensin-modifying agents and statins within 90 days after hospital discharge in 2005/06

\begin{tabular}{|c|c|c|c|c|}
\hline \multirow[b]{2}{*}{ Characteristic } & \multirow[b]{2}{*}{$\begin{array}{l}\text { No. (\%) of patients } \\
\quad n=8706\end{array}$} & \multicolumn{3}{|c|}{$\%$ of patients who filled a prescription } \\
\hline & & $\beta$-Blockers & $\begin{array}{l}\text { Angiotensin- } \\
\text { modifying agents }\end{array}$ & Statins \\
\hline \multicolumn{5}{|l|}{ Physician } \\
\hline \multicolumn{5}{|l|}{ Specialty } \\
\hline Cardiology & $4043(46.4)$ & 81.4 & 81.3 & 86.0 \\
\hline General internal medicine & $1673(19.2)$ & 77.0 & 77.8 & 79.2 \\
\hline Other specialty & $869(10.0)$ & 75.9 & 74.9 & 77.2 \\
\hline General or family practice & $2121(24.4)$ & 74.3 & 75.3 & 68.4 \\
\hline \multicolumn{5}{|c|}{$\begin{array}{l}\text { No. of myocardial infarction cases } \\
\text { in } 2005\end{array}$} \\
\hline $1-5$ & $2112(24.3)$ & 74.9 & 74.0 & 70.1 \\
\hline $6-17$ & $2311(26.5)$ & 78.2 & 79.7 & 79.6 \\
\hline $18-32$ & $2133(24.5)$ & 80.2 & 79.3 & 84.0 \\
\hline$>32$ & $2150(24.7)$ & 79.8 & 80.8 & 84.3 \\
\hline \multicolumn{5}{|l|}{ Clinical experience, $y r$} \\
\hline$<15$ & $2227(25.6)$ & 80.2 & 78.7 & 80.2 \\
\hline $15-22$ & $2228(25.6)$ & 80.0 & 79.3 & 82.2 \\
\hline $23-28$ & $2040(23.4)$ & 78.2 & 80.0 & 78.6 \\
\hline$\geq 29$ & $2211(25.4)$ & 74.6 & 76.2 & 77.0 \\
\hline \multicolumn{5}{|l|}{ Sex } \\
\hline Women & $1197(13.7)$ & 78.7 & 78.6 & 77.1 \\
\hline Men & $7509(86.3)$ & 78.2 & 78.5 & 79.9 \\
\hline \multicolumn{5}{|l|}{ Hospital } \\
\hline \multicolumn{5}{|l|}{ Cardiac procedures } \\
\hline None & $6263(71.9)$ & 78.3 & 78.8 & 78.2 \\
\hline Catheterization only & $857 \quad(9.8)$ & 72.8 & 73.9 & 79.3 \\
\hline Revascularization & $1586(18.2)$ & 81.1 & 79.7 & 84.9 \\
\hline \multicolumn{5}{|l|}{ Teaching status } \\
\hline No & $7163(82.3)$ & 77.5 & 78.1 & 78.0 \\
\hline Yes & $1543(17.7)$ & 81.7 & 80.6 & 86.4 \\
\hline \multicolumn{5}{|c|}{$\begin{array}{l}\text { No. of myocardial infarction cases } \\
\text { in } 2005 / 06\end{array}$} \\
\hline$\leq 100$ & $1695(19.5)$ & 75.1 & 78.6 & 76.5 \\
\hline $101-200$ & $1945(22.3)$ & 78.7 & 78.6 & 77.6 \\
\hline $201-300$ & $2981(34.2)$ & 79.4 & 78.4 & 82.0 \\
\hline$>300$ & $2085(23.9)$ & 78.9 & 78.6 & 80.1 \\
\hline \multicolumn{5}{|c|}{ Community size, no. of people } \\
\hline$\geq 1250000$ & $1707(19.6)$ & 80.5 & 80.3 & 84.7 \\
\hline 500 000-1 249999 & $872(10.0)$ & 82.5 & 78.1 & 84.2 \\
\hline 100 000-499999 & $2480(28.5)$ & 78.9 & 76.9 & 78.5 \\
\hline$<100000$ & 3647 (41.9) & 75.8 & 78.8 & 76.7 \\
\hline
\end{tabular}


of each of the 3 medications. The odds of using $\beta$-blockers decreased by $2 \%$ (adjusted OR $0.98,95 \%$ confidence interval [CI] 0.97-0.99) for each 1-year increase in age; similarly, the odds of using angiotensin-modifying agents decreased by $3 \%$ (adjusted OR 0.97, 95\% CI 0.97-0.98) for each 1-year increase, and the odds of using statins decreased by 6\% (adjusted OR 0.94, 95\% CI 0.93-0.95) for each 1-year increase. The presence of cancer and cardiac dysrhythmias was also associated with lower use of each of the 3 medications.

\section{Physician characteristics}

Having a general practitioner or family practitioner, a general internist or another noncardiology specialist as an attending physician was associated with significantly lower odds of postdischarge use of each of the 3 classes of medication, relative to having a cardiologist as an attending physician (odds ratios ranging from 0.46 to 0.82 ). Having an attending physician with at least 29 years clinical experience was associated with significantly lower odds of receiving $\beta$-blockers and statins, relative to having an attending physician with fewer than 14 years of experience (adjusted odds ratio $0.71,95 \%$ CI $0.60-0.84$ for $\beta$ blockers; adjusted odds ratio $0.81,95 \%$ CI $0.67-0.97$ for statins). The effect of having an attending physician with at least 29 years of clinical experience relative to one with fewer than 14 years of experience on the odds of receiving angiotensin-modifying drugs showed a trend toward statistical significance (adjusted odds ratio $0.86,95 \%$ CI $0.74-1.01$ ). Physicians' volume of myocardial infarction cases was not independently associated with drug use after discharge.

\section{Hospital characteristics}

Most patients (71.9\%) received treatment at hospitals without the capacity for invasive cardiac procedures, and $17.7 \%$ of patients received treatment at teaching hospitals (Table 2). Being treated at a hospital with catheterization-only capacity was associated with lower odds of filling a prescription for a $\beta$-blocker (adjusted odds ratio $0.63,95 \%$ CI $0.47-0.85$ ) or an angiotensin-modifying agent (adjusted odds ratio $0.71,95 \%$ CI 0.54-0.92), relative to being treated at a hospital without the capacity for invasive cardiac procedures. Compared with receiving treatment at a nonteaching hospital, receiving treatment at a teaching hospital was associated with greater odds of filling a prescription for a statin (adjusted odds ratio 1.64, 95\% CI 1.14-2.34). Hospital volume of patients with myocardial infarction was not independently associated with the use of these drugs after discharge.

We identified 73 hospitals that had discharged at least 30 elderly patients with myocardial infarction in 2005/06 (Table 3). The capacity for invasive cardiac procedures differed significantly between hospitals with low and high use of $\beta$-blockers $(p=0.044)$ and between hospitals with low and high use of angiotensin-modifying agents $(p=0.036)$. Hospi-

Table 3: Characteristics of 73 hospitals with low and high rates of postdischarge prescribing of $\beta$-blockers, angiotensin-modifying agents and statins to elderly patients with myocardial infarction in 2005/06

\begin{tabular}{|c|c|c|c|c|c|c|}
\hline \multirow[b]{2}{*}{ Characteristic } & \multicolumn{2}{|c|}{$\begin{array}{c}\beta \text {-blockers; } \\
\% \text { of hospitals }\end{array}$} & \multicolumn{2}{|c|}{$\begin{array}{l}\text { Angiotensin-modifying agents; } \\
\% \text { of hospitals }\end{array}$} & \multicolumn{2}{|c|}{$\begin{array}{l}\text { Statins; } \\
\% \text { of hospitals }\end{array}$} \\
\hline & $\begin{array}{c}\text { Low-prescribing } \\
\text { hospital* } \\
n=39\end{array}$ & $\begin{array}{l}\text { High-prescribing } \\
\text { hospital } \dagger \\
n=34\end{array}$ & $\begin{array}{l}\text { Low-prescribing } \\
\text { hospital } \\
n=44\end{array}$ & $\begin{array}{c}\text { High-prescribing } \\
\text { hospital } \\
n=29\end{array}$ & $\begin{array}{c}\text { Low-prescribing } \\
\text { hospital } \\
n=35\end{array}$ & $\begin{array}{c}\text { High-prescribing } \\
\text { hospital } \\
n=38\end{array}$ \\
\hline \multicolumn{7}{|l|}{$\begin{array}{l}\text { No. of myocardial } \\
\text { infarction cases } \\
\text { in } 2005 / 06\end{array}$} \\
\hline$\leq 100$ & 23 & 15 & 21 & 17 & 20 & 18 \\
\hline $101-200$ & 28 & 38 & 30 & 38 & 43 & 24 \\
\hline $201-300$ & 31 & 35 & 36 & 28 & 23 & 42 \\
\hline$>300$ & 18 & 12 & 14 & 17 & 14 & 16 \\
\hline Teaching hospital & 13 & 21 & 11 & 24 & 6 & 26 \\
\hline \multicolumn{7}{|l|}{ Cardiac procedures } \\
\hline None & 74 & 79 & 77 & 76 & 83 & 71 \\
\hline Catheterization only & 15 & 0 & 14 & 0 & 9 & 8 \\
\hline Revascularization & 10 & 21 & 9 & 24 & 9 & 21 \\
\hline \multicolumn{7}{|l|}{$\begin{array}{l}\text { Community size, } \\
\text { no. of people }\end{array}$} \\
\hline$\geq 1250000$ & 8 & 29 & 11 & 28 & 9 & 26 \\
\hline $500000-1249999$ & 3 & 15 & 9 & 7 & 6 & 11 \\
\hline $100000-499999$ & 28 & 21 & 27 & 21 & 26 & 24 \\
\hline$<100000$ & 62 & 35 & 52 & 45 & 60 & 40 \\
\hline
\end{tabular}

*Low-prescribing hospitals were defined as those where less than $80 \%$ of patients with myocardial infarction were given a prescription for the particular drug at discharge.

tHigh-prescribing hospitals were defined as those where at least $80 \%$ of patients were given a prescription for the particular drug at discharge. 

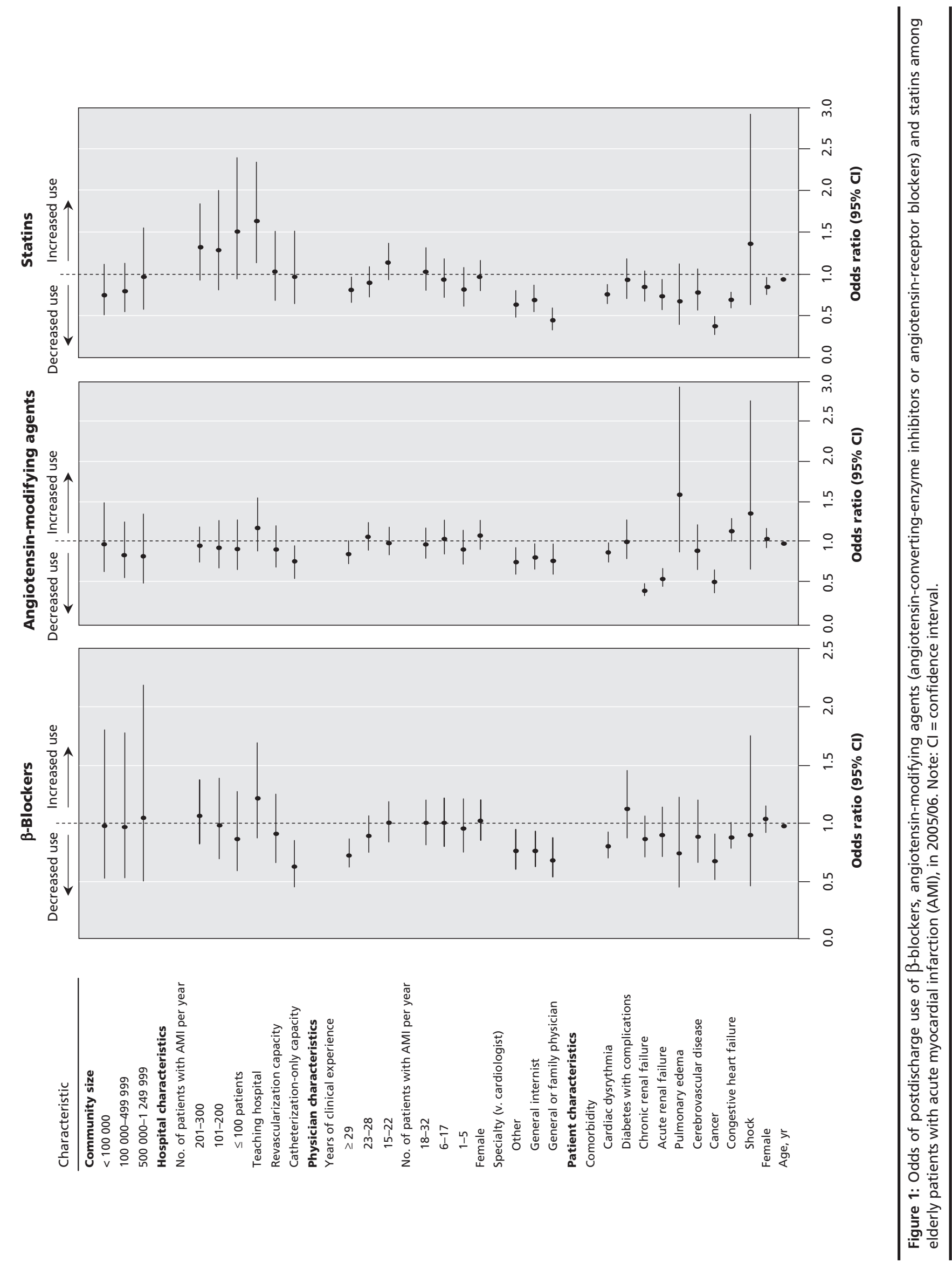
tals with high prescribing of these medications were more likely than those with low prescribing to have the capacity for cardiac revascularization $(21 \%$ v. $10 \%$ for high v. low prescribing of $\beta$-blockers; $24 \%$ v. 9\% for high v. low prescribing of angiotensin-modifying agents). Hospitals with high prescribing of statins were more likely than those with low prescribing to be teaching facilities ( $26 \%$ v. $6 \%$ for high v. low prescribing of statins; $p=0.026$ ). Finally, hospitals with high postdischarge prescribing of $\beta$-blockers tended to be located in communities of different sizes than those with low postdischarge use of this drug category $(p=0.009)$. Hospitals with high postdischarge prescribing of statins were more likely than those with low prescribing to be located in communities with at least 1250000 residents (26\% v. 9\%).

The effect of patient, physician, hospital and community characteristics on the postdischarge use of $\beta$-blockers, angiotensin-modifying agents and statins are shown in Figure 1 and are reported in detail in Appendix 1 (available online at www.cmaj.ca/cgi/content/full/179/9/901/DC2).

\section{Community characteristics}

About one-fifth (19.6\%) of patients lived in very large communities ( $\geq 1250000$ people) (Table 1), and nearly half (41.9\%) lived in communities of less than 100000 residents. Community size was not independently associated with postdischarge drug use.

\section{Interpretation}

Among patients with myocardial infarction who were discharged from hospital in 2005, a variety of patient, physician and hospital characteristics accounted for differences in the use of evidence-based drug therapies after discharge. For example, having a general practitioner or family practitioner, a general internist or a different specialist as an attending physician, rather than a cardiologist, was associated with 19\%-55\% lower odds of postdischarge use of each of the 3 classes of medications. Having an attending physician with at least 29 years of clinical experience, relative to fewer than 14 years of clinical experience, was associated with $28 \%$ decreased odds of receiving a $\beta$-blocker and $19 \%$ lower odds of receiving a statin.

In a companion study in this issue of $C M A J$, we found moderate variability between hospitals in the use of evidence-based drug therapies among elderly patients after discharge with myocardial infarction. ${ }^{1}$ In this study, after adjustment for patient and physician characteristics, we found that many of the differences between hospitals that had been consistent across different classes of medications were no longer evident. Our findings on the association between physician characteristics and postdischarge drug use by patients with myocardial infarction complement those of an earlier Ontario study, in which there was an inverse relation between the annual volume of patients with myocardial infarction attended by admitting physicians and patient mortality.$^{10}$ In the current study, we also found that the use of evidence-based drug therapies decreased with increasing patient age, a finding that is consistent with previous studies. ${ }^{16,17} \mathrm{In}$ this regard, our findings build upon those prior studies, by demonstrating that the importance of age in influencing prescribing patterns persists after adjustment for physician, hospital and community characteristics. Similarly, the impact of the specialty of the attending physician on the use of evidence-based drug therapies builds upon previous evidence of lower prescribing rates of $\beta$-blockers among general practitioners and family practitioners than among cardiology specialists. ${ }^{18,19}$ Previous studies also showed higher postdischarge use of $\beta$-blockers among patients attended by cardiologists than among those attended by other physicians. ${ }^{20,21}$ Our findings were similar to those of an earlier study in which physicians who were more recent graduates of medical school were more likely to prescribe $\beta$-blockers after myocardial infarction. ${ }^{21}$

In the current study, we found that patients attended by noncardiologists had a lower likelihood of filling prescriptions for evidence-based drug therapies within 90 days after discharge from hospital compared with patients attended by cardiologists. These differences are likely due, at least in part, to cardiologists' greater knowledge of appropriate drug therapy for patients with myocardial infarction. However, another partial explanation for this finding could be that cardiologists have patients who are younger and have less comorbid illness than patients seen by other physicians. Therefore, with fewer contraindications to therapy, these patients may be more likely to be ideal candidates for therapy and to receive a prescription at discharge. We also found that patients attended by physicians with at least 29 years of clinical experience had lower postdischarge use of medical therapy than patients attended by physicians with less than 14 years of experience. These differences may reflect changes in medical education, whereby physicians trained more recently may have had greater exposure to evidence-based medicine. Furthermore, the evidence for the use of these therapies accumulated during the period when many of the more recently trained physicians were undergoing their medical training.

Our study suggests that there is a need to develop more effective mechanisms for knowledge translation to improve the clinical practice of noncardiology specialists and of physicians who have been in clinical practice for a long time. We speculate that the development and widespread dissemination of standardized discharge orders for patients with myocardial infarction could improve the delivery of evidence-based drug therapies.

\section{Limitations}

Our study has certain limitations, several of which are described in our study examining the temporal trends in the use of these therapies. ${ }^{1}$ A primary limitation involved the use of physician billing claims to identify the attending physician. Consequently, physicians who practised under alternate payment plans and who did not submit "shadow" billings to the Ontario Health Insurance Plan would not have been identified in our study. We therefore excluded patients for whom attending physician specialty was not available. However, physicians practising under alternate 
payment plans and not submitting "shadow" bills to the Ontario Health Insurance Plan probably constitute a small minority of physicians in Ontario. ${ }^{22}$

\section{Conclusions}

Patient and physician characteristics were associated with postdischarge use of $\beta$-blockers, angiotensin-modifying agents and statins among patients with myocardial infarction in Ontario in 2005/06. Further research is required to determine how to improve prescribing by physicians with suboptimal prescribing practices. In particular, there is an opportunity to explore and develop new methods of knowledge translation aimed at physicians who have been in clinical practice for a long time and whose training in medical school and residency may not correspond with current clinical practice guidelines. Furthermore, there is a need to explore methods to improve discharge prescribing by noncardiologists. Patients under the care of general internists, general and family practitioners, and other specialists had lower postdischarge use of the study medications than those under the care of cardiologists. However, in many settings, it is not feasible for all patients with myocardial infarction to have a cardiologist as an attending physician. Further research is required to develop mechanisms to improve prescribing in these settings.

\section{This article has been peer reviewed.}

Competing interests: David Alter is the chief scientific officer of INTERxVENT Canada. No competing interests declared by Peter Austin, Jack Tu or Dennis Ko.

Contributors: Peter Austin and Jack Tu conceived the study and its design, and contributed to the acquisition of data. Peter Austin conducted the statistical analyses. Each of the authors contributed substantially to the interpretation of data. Peter Austin drafted the article, and each of the authors revised the manuscript critically for important intellectual content. All of the authors approved the final version to be published. Peter Austin had full access to all of the data in the study and takes responsibility for the integrity of the data and the accuracy of the data analysis.

Acknowledgements: The Institute for Clinical Evaluative Sciences is supported in part by a grant from the Ontario Ministry of Health and Long-Term Care. The opinions, results and conclusions presented here are those of the authors, and no endorsement by the Ontario Ministry of Health and LongTerm Care or by the Institute for Clinical Evaluative Sciences is intended or should be inferred.

Peter Austin is supported in part by a Career Scientist Award from the Heart and Stroke Foundation of Ontario. Dennis Ko is supported by a Clinician-Scientist Award by the Heart and Stroke Foundation of Ontario. Jack Tu holds a Canada Research Chair in Health Services Research and a Career Investigator Award from the Heart and Stroke Foundation of Ontario.

Funding: This research was supported by an operating grant from the Heart and Stroke Foundation of Ontario and a Canadian Institutes of Health Research Team Grant in Cardiovascular Outcomes Research.

\section{REFERENCES}

1. Austin PC, Tu JV, Ko DT, et al. Use of evidence-based therapies after discharge among elderly patients with acute myocardial infarction. CMAJ 2008;179:895-900.

2. Soumerai SB, McLaughlin TJ, Spiegelman D, et al. Adverse outcomes of underuse of $\beta$-blockers in elderly survivors of acute myocardial infarction. JAMA 1997 ; 277:115-21

3. Gurwitz JH, Goldberg RJ, Chen Z, et al. $\beta$-Blocker therapy in acute myocardial infarction: evidence for underutilization in the elderly. Am J Med 1992;93:605-10.

4. Barron HV, Michaels AD, Maynard C, et al. Use of antiotensin-converting enzyme inhibitors at discharge in patients with acute myocardial infarction in the United States: data from the National Registry of Myocardial Infarction 2. J Am Coll Cardiol 1998;32:360-7.

5. Rochon PA, Anderson GM, Tu JV, et al. Use of $\beta$-blocker therapy in older patients after acute myocardial infarction in Ontario. CMAJ 1999;161:1403-8.

6. Dwamena FC, El-Tamimi H, Watson RE, et al. The use of angiotensin-converting enzyme inhibitors in patients with acute myocardial infarction in community hospitals. Michigan State University Inter-Institutional Collaborative Heart (MICH) Study Group. Clin Cardiol 2000;23:341-6.

7. Tu JV, Naylor CD, Austin P. Temporal changes in the outcomes of acute myocardial infarction in Ontario, 1992-96. CMAJ 1999;161:1257-61.

8. Tu JV, Austin P, Naylor CD, et al. Acute myocardial infarction outcomes in Ontario. In: Naylor CD, Slaughter PM, editors. Cardiovascular health and services in Ontario: an ICES atlas. Toronto: Institute for Clinical Evaluative Sciences; 1999. p. 83-110.

9. Austin PC, Daly PA, Tu JV. A multicenter study of the coding accuracy of hospital discharge administrative data for cardiac care unit patients in Ontario. Am Heart $J$ 2002;144:290-6.

10. Tu JV, Austin PC, Chan BTB. Relationship between annual volume of patients treated by admitting physician and mortality after acute myocardial infarction. JAMA 2001;285:3116-22.

11. Ko DT, Austin PC, Chan B, et al. Quality of care of international and Canadian medical graduates in acute myocardial infarction. Arch Intern Med 2005;165:458-63.

12. Austin PC, Goel V, van Walraven C. An introduction to multilevel regression models. Can J Public Health 2001;92:150-4.

13. Austin PC, Tu JV, Alter DA. Comparing hierarchical modeling with traditional logistic regression analysis among patients hospitalized with acute myocardial infarction: Should we be analyzing cardiovascular outcomes data differently? Am Heart J 2003;145:27-35.

14. Goldstein H. Multilevel statistical models. 2nd ed. London (UK): Edward Arnold; 1995.

15. Tu JV, Austin PC, Walld R, et al. Development and validation of the Ontario acute myocardial mortality prediction rules. J Am Coll Cardiol 2001;37:992-7.

16. Ganz DA, Lamas GA, Orav EJ, et al.; Pacemaker Selection in the Elderly (PASE) Investigators. Age-related differences in management of heart disease: a study of cardiac medication use in an older cohort. J Am Geriatr Soc 1999;47:145-50.

17. Sial SH, Malone M, Freeman JL, et al. Beta blocker use in the treatment of community hospital patients discharged after myocardial infarction. J Gen Intern Med 1994;9:599-605.

18. Krumholz HM, Radford MJ, Wang Y, et al. National use and effectiveness of $\beta$ blockers for the treatment of elderly patients with acute myocardial infarction. JAMA 1998;280:623-9.

19. Fehrenbach SN, Budnitz DS, Gazmararian JA, et al. Physician characteristics and the initiation of beta-adrenergic blocking agent therapy after acute myocardial infarction in a managed care population. Am J Manag Care 2001;7:717-23.

20. Granger CB, Steg PG, Peterson E, et al. Medication performance measures and mortality following acute coronary syndromes. Am J Med 2005;118:858-65.

21. Levy AR, Tamblyn RM, McLeod PJ, et al. The effect of physicians' training on prescribing beta-blockers for secondary prevention of myocardial infarction in the elderly. Ann Epidemiol 2002;12:86-9.

22. Jaakkimainen L, Upshur REG, Klein-Geltink JE, et al. ExecutivesSummary. In Jaakkimainen L, Upshur REG, Klein-Geltink JE, et al., editors. Primary care in Ontario: ICES atlas. Toronto (ON): Institute for Clinical Evaluative Sciences; 2006.

Correspondence to: Dr. Peter C. Austin, Institute for Clinical Evaluative Sciences, Rm. G1 06, 2075 Bayview Ave., Toronto ON M4N 3M5; fax 416 480-6048; peter.austin@ices.on.ca 